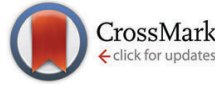

Cite this: DOI: 10.1039/c4cc04378b

Received 9th June 2014

Accepted 21st July 2014

DOI: $10.1039 / c 4 c c 04378 b$

www.rsc.org/chemcomm

\section{Catalyst free silica templated porous carbon nanoparticles from bio-waste materials $\dagger$}

\author{
Anuj Kumar, ${ }^{a b}$ Gurumurthy Hegde, ${ }^{\text {a }}$ Shoriya Aruni Bt Abdul Manaf, ${ }^{a}$ Z. Ngaini ${ }^{c}$ and \\ K. V. Sharma
}

Porous Carbon Nanoparticles (PCNs) with well-developed microporosity were obtained from bio-waste oil palm leaves (OPL) using single step pyrolysis in nitrogen atmosphere at $500-600^{\circ} \mathrm{C}$ in tubefurnace without any catalysis support. The key approach was using silica $\left(\mathrm{SiO}_{2}\right)$ bodies of $\mathrm{OPL}$ as a template in the synthesis of microporous carbon nanoparticles with very small particle sizes of 35-85 $\mathrm{nm}$ and pore sizes between 1.9-2 $\mathrm{nm}$.

In modern-day scientific applications, porous nanocarbons are ubiquitous and indispensable. Porous carbon, ${ }^{1}$ carbon nanotubes, ${ }^{2}$ fullerenes, ${ }^{3}$ and graphenes ${ }^{4}$ formed an innovative class of nanocarbons having various applications in electronics, ${ }^{5}$ environment, ${ }^{6}$ energy, ${ }^{7}$ and catalyses, ${ }^{8}$ etc. Porous carbons can be classified according to their pore diameters as microporous (pore size $<2 \mathrm{~nm}$ ), mesoporous ( $2 \mathrm{~nm}<$ pore size $<50 \mathrm{~nm}$ ), and/or macroporous (pore size $>50 \mathrm{~nm}$ ). ${ }^{9}$ The nanoporous carbons are fabricated by templating methods. ${ }^{10}$ In template synthesis, an artificial silica template is formed along with the carbon source. Afterward, the template is carbonized and the excess silica is removed via a chemical process to obtain porous carbon. ${ }^{11}$ However, the template and the carbon sources are usually two incompatible materials. ${ }^{12}$ Hard-templating and soft-templating are the two main templating methods used in the fabrication of porous carbons; both these methods have certain limitations and drawbacks. ${ }^{13}$ The synthesis route involves the impregnation of a silica template with a carbon precursor followed by the carbonization of the resulting composite and template removal known as hard template. ${ }^{14}$

\footnotetext{
${ }^{a}$ Faculty of Industrial Sciences \& Technology, Universiti Malaysia Pahang, Gambang 26300, Kuantan, Pahang, Malaysia. E-mail: murthyhegde@gmail.com, hegde@ump.edu.my

${ }^{b}$ Czech Technical University in Prague, Faculty of Civil Engineering Department of Building Structures, Thákurova 7, 16629 Praha 6, Czech Republic

Centre for Technology, Transfer \& Consultancy (CTTC), University Malaysia Sarawak, 94300 Kota Samarahan, Sarawak, Malaysia

${ }^{d}$ Department of Mechanical Engineering, Faculty of Engineering, University Technology PETRONAS, Bandar Seri Iskandar, 31750, Tronoh, Perak, Malaysia $\dagger$ Electronic supplementary information (ESI) available. See DOI: 10.1039/ c4cc04378b
}

The silica based template is commonly used to fabricate the well-developed porous carbons because silica have natural porous structures and provide an appropriate platform for porous carbon fabrication. ${ }^{14}$ Resorcinol formaldehyde, furfuryl alcohol, phenol, and sucrose are mainly used as carbon precursors and inorganic templates, including zeolites, colloidal silica, and mesoporous silica. ${ }^{15}$ In this two-step template synthesis, the porous carbons have precise pore size and pore structure but have certain limitations such as high cost, time consuming infiltration steps, and the formation of nonporous carbon on template. ${ }^{16}$ One-step template synthesis of porous carbon carried out by the carbonization of organic aerogels (supercritical $\left.\mathrm{CO}_{2}\right)^{17}$ and the nanocomposite of carbon precursor and silica precursor was followed by polymerization and carbonization steps. ${ }^{18}$

Herein, we describe a new carbon precursor referred to as oil palm leaves (OPL), a waste lignocellulose biomass from oil palm industries which is abundant in south-east Asia. ${ }^{19}$ OPL consists of $47.7 \%$ holocellulose, $44.53 \% \alpha$-cellulose and $27.35 \%$ lignin and extractives of around $20.60 \% .^{20}$ We have analysed the distribution and locations of silica particles in OPL using electron microscopy (FESEM) (Fig. S1a-d, ESI $\dagger$ ) and energy dispersive X-ray (EDX) analysis. The EDX result estimate was around $13.30 \%$ of silica in raw OPL (Fig. S1e, ESI $\dagger$ ). The silica particles are accumulated in the epidermal tissue or the cell wall of leaves where transpiration induces loss of water, which in turn increases the concentration of silica. ${ }^{21}$ The occurrence of $\mathrm{Si}$ within the plant is because of its uptake, in the form of soluble $\mathrm{Si}(\mathrm{OH})_{4}$ or $\mathrm{Si}(\mathrm{OH})_{3} \mathrm{O}-$, from soil and its controlled polymerization at a final location. ${ }^{22}$ The individual silica bodies consist of about 100000 silica rods, and the silica particles in each rod have a diameter of 1-2 $\mathrm{nm} .^{23}$

The FTIR analysis of OPL revealed the presence of the $\mathrm{Si}-\mathrm{H}$ bond; namely the absorption bands at $655 \mathrm{~cm}^{-1}$ are attributed to the stretching mode of the mono-hydrogen bond $(\mathrm{Si}-\mathrm{H}) \cdot{ }^{24} \mathrm{An}$ absorption band at $1409 \mathrm{~cm}^{-1}$ appearing for $\mathrm{Si}-\mathrm{CH}_{3}$ confirms the presence of Si in OPL (Fig. S2a, ESI $\dagger$ ). The $\mathrm{Si}-\mathrm{O}$ vibrations at $1050 \mathrm{~cm}^{-1}$ are because of stretching vibration where the 